\title{
CZECH CONSUMER ON THE LUXURY SKINCARE COSMETICS MARKET
}

\author{
[Český spotřebitel na trhu luxusní plet’ové kosmetiky]
}

\author{
Dorota Anderlová ${ }^{1}$ \\ ${ }^{1}$ Mendel University in Brno, Faculty of Business and Economics, Zemédèlská 1, 61300 Brno \\ Email: xanderl1@mendelu.cz
}

\begin{abstract}
The article aims to discover consumer preferences concerning luxury skincare products by applying the multivariate statistical method, a conjoint analysis. The main aim is to identify the significant attributes of products influencing consumer behaviour in terms of purchase, use, motivation, and a general approach to the luxury skincare product segment on the Czech market. The main sources for primary data are questionnaire surveys and in-depth interviews with representatives of companies operating in this sector. According to the initial analysis, four of the most significant attributes were determined that apply to consumer behaviour within this sector and the product in question: the possibility of product sampling, point of sale advice, product price, and level of the special offer. Using the conjoint analysis, these attributes were incorporated into individual model cards and subsequently offered to consumers for rating. The final sample of 1,104 respondents rated the offered product variants of skincare products, with the result that that the most preferred factors were price and amount of the special offer, as opposed to less-preferred products offering sampling and point of sale advice. Simultaneously, the data showed that consumers gave most preference to the lowest price and the highest special offer.
\end{abstract}

Keywords: conjoint analysis, consumer behaviour, influencing factors, luxury goods, skincare products.

JEL classification: D12, D91, M31, L66

Received: 11.3.2021; Reviewed: 30.4.2021; 21.6.2021; Accepted: 3.11.2021

\section{Introduction}

This article aims to identify the significant factors that influence consumer behaviour in the luxury skincare products sector, rate their significance and deduce conclusions and recommendations for entities from the cosmetics industry. Currently, the goal of successful business firms, production companies and organizations is to choose an effective marketing and business strategy and apply it to a specific product or service within the market sector. One of the preconditions for achieving this success must be knowledge of the consumer. Understanding and recognizing consumer behaviour, adjusting the offer of a product or service to the needs and expectations of the consumer are all key elements. In view of the dynamically changing market environment, changes in consumer preferences, and appearance of new factors influencing consumer decision-making, it is necessary to constantly adapt a strategy based on current consumer surveys. The article contributes to the understanding of consumer behaviour in the luxury skincare product sector with the incorporation of current changes.

\section{Literature review}

\section{Consumer behaviour - luxury goods}

Human consumer behaviour represents the area of human behaviour that involves the acquisition and subsequent use of consumer products. This behaviour is unquestionably linked to each individual and is highly subjective. Koudelka (2006) points out that consumer behaviour is influenced partly by genetics nevertheless the reasons, ways and other 
influencing factors that have an impact on consumer behaviour are also acquired throughout a person's life. The resulting display of consumer behaviour is the purchase of a certain product while buying behaviour is affected by a series of factors which, when interconnected, create a specific form of the consumer's buying decision. This may be rational, economic, psychological, emotional, sociological and cultural factors. So the consumer is affected in his buying decision not just by his predispositions, attitudes and values, but also by his environment, marketing incentives and social groups.

The success of all organizations lies in the hands of the consumers. Their needs, wishes and buying behaviour must be understood. Consumer behaviour during a purchase is defined as an analysis of when, where, how and why people buy a certain product. The purchase of beauty products depends on various attributes which is the price, quality, the brand name and brand trust. Currently consumers prefer quality and brand products. At one time it was price that was the sole factor affecting consumer behaviour. However, now besides, the low price, the important factor is the brand (Vidyapeeth 2018). According to Loureiro (2012), there is a rise in so-called CBR (consumer-brand relationship), i.e. the relationship between the brand and consumer, the importance for an increasing number of companies. However, it has also gained attention among researchers and experts who are trying to discover why some brands are preferred more than others, why some brands are even loved and as a consequence they try to determine the relationship created between the consumer and brand.

Furthermore, studies on the consumer behaviour of a cosmetic product (Yeh et al. 2010) describe various theories and models such as: TPB (theory of planned behavior) and TRA (theory of reason action), where these theories associate psychologically conditioned behavior associated with value model leading to the prediction of the consumer model. Although approaches are different, the basic knowledge is a significant influence of consumer behavior of cosmetics purchases by psycho-social influences, i.e. personal values, attitudes and patterns of behaviour (Ajitha, S. Sivakumar, V. J. 2017)

The area of luxury products possesses specific characteristics with regard to consumer behaviour. The word 'luxury' is derived from the Latin word 'luxus' which means opulence, exuberance and sumptuousness (Tak \& Pareek 2016). The concept of "luxury" continues to develop and change and what is considered a luxury today, may be something ordinary tomorrow. The perception of luxury may also differ culturally, individually, or at national level: what is "luxury" or culture for one person may not be the case for another (Park \& Reisinger 2009). The importance of symbolic significance is often attributed to the consumption of luxury goods. Symbolic importance is often attributed to the consumption of luxury products (Tak \& Pareek 2016). Overpricing, aesthetics, uniqueness and symbolism are key elements of luxury (Dubois et al. 2001). Some consumers regard the term "luxury" to be a feeling of prestige which is very often associated with certain social status (Correia et al. 2018). The findings of Okonkwo (2009) speak of the consumption of luxury brands as a concept of luxury such as "identity, philosophy and culture". Even other scientific studies confirm this view of luxury consumption. The results of the research (Chan et al. 2015, Han et al. 2010) speak of the attraction of consumers to visible brands to display their own wealth. At the same time, luxury consumption is closely associated with social status (Kastanakis \& Balabanis 2014) and a way of striving for individuality (Gentina et al. 2016). Other frequent attributes of luxury products are their high price and quality, which provide the consumer with a feeling of prestige, exceptional experience and perception of rarity (Rolling \& Sadachar 2018). The results of the study by Semaan (2019) also, of course, indicate the possibility of the existence of different levels of luxury based on material or design. 


\section{Consumer behaviour - skincare products}

The article focuses on consumer behaviour in the luxury skincare product sector as a consumer segment with certain specifics. Khuong and Duyen (2016) confirm that appearance, skin healthcare, body attraction, age, and the aging process significantly influence a consumer's decision to purchase skincare products. Most women use cosmetic products to improve their physical, youthful appearance and self-confidence (Junaid et al. 2013). The study by $\mathrm{Wu}$ and Chan (2011) focuses on cosmetics and skincare products, stressing the importance of the quality of services regarded by consumers and their concepts which support their attitudes, purchasing intentions and behaviour, even satisfaction and loyalty. The results of the research (Duh \& Tshabalala 2019) also show that brands play an important role in the cosmetics sector. The attitude to cosmetic brands is influenced by the attraction of celebrities, credibility, and symbolic value ascribed to this brand. The intention of the purchase can be predicted, depending on the attitude to brands.

The cosmetics and skincare market is naturally strongly competitive and focuses predominantly on women. Consumers are linked to specific skincare brands and above all, to the quality and apparent effects of individual brand products (Akhtar et al. 2016). In research carried out in the US, focusing on the distinguishing features of luxury cosmetics, most consumers stated that the brand, quality and price are the attributes that distinguish luxury cosmetic products from the rest (Statista 2019).

Based on the above theoretical background, studies outputs and research conclusions the following question has been established within this study for further research: What are the key significant factor influencing consumer behaviour in connection to luxury cosmetics on the Czech market?

\section{Methodology and data}

\section{Conjoint analysis}

In this study, the statistical method used is conjoint analysis, which is a specific technique used to determine which variables characterizing products and services most influence the choice of product and which combination of categories of these variables is most preferred by consumers. The basis is an analysis of variance which is applied to ordinal variables expressing consumer preference. In view of the fact that the preference analysis does not meet the standard preconditions for variance analysis, the results are based on approximations (IASTAT 2001). The conjoint analysis helps in understanding the way consumers create preferences for a certain type of product or service. It ensures the utility which consumers ascribe to different attributes of a specific product, and therefore helps to determine which of these attributes have the greatest influence on the choice of product, and also what combination of variables the consumer most prefers (Hair 2010). The conjoint analysis is considered the most realistic form in view of the simulation of choice situations that are very similar to actual consumer decision-making, with the presentation of all attributes considered relevant for an alternative and the choice they provide (Bahamonde 2017).

\section{Definition of attributes and their levels}

The market segment, in which this study took place, was defined as retail stores, i.e. the perfume shop segment in the Czech Republic. As a representative of this segment, a local FAnn perfumery chain was selected, which reaches a significant market share in this cosmetics sector, concretely $38 \%$ share on the Czech cosmetics market As already mentioned above, the term "luxury" can differ generally in quality, materials, price, or consumer 
perception. Moreover, it differs across the various industries. As there is not any clear definition of the term "luxury" in skincare segment, therefore based on the long-term expert experience, luxury skincare products were defined as follows: skincare product with the price above $3.000 \mathrm{CZK}$ per $50 \mathrm{ml}$ product bearing worldwide luxury brand names such as Estée Lauder, Chanel, Dior, La Prairie, and Sisley.

Based on the literature review and in-depth interviews with cosmetics industry representatives, the most significant factors were named applying to luxury skincare products on the Czech market. The in-depth interviews took place in FAnn perfumery headquarters with ten representatives from key FAnn department, concretely: general manager, managing director, retail manager, marketing manager, area manager South Moravia region, area manager Bohemia region, store manager Prague store, e-shop manager FAnn, senior manager luxury skincare and key account manager luxury. The questionnaire consisted of 25 questions divided into 4 theme parts: luxury cosmetics, consumer habits, cosmetics brands and marketing tools. Each interview lasted around 45 minutes.

Afterwards, the influencing factors were determined as follows: product ingredients (efficacy), product brand, product price, special price offer, product sampling, the possibility of point of sale advice, product appearance, recommended by friends/family - social status. Then, during three weeks in June 2020, these factors were incorporated into a questionnaire survey and presented for completion to consumers of FAnn parfumerie. Consumers were included from the customer database with previous experience of the skincare products of the above luxury brands. The resulting sample contained a total of 892 completed questionnaires. Subsequently, four of the most significant attributes were determined according to the frequency of answers in the survey results. The last step to confirm the appropriate choice of significant factors was again in-depth interviews with representatives of the cosmetics sector when individual levels of selected attributes were simultaneously consulted and finally supplemented. Based on the above steps, the following four most significant attributes were selected: product sampling, the possibility of point of sale advice (POS advice, product price (product value) and a special offer (amount of the offered product discount), the attributes and their individual levels are shown in Table 1:

Table 1: Attributes and their levels

\begin{tabular}{|c|c|c|c|c|}
\hline Level & Special offer & $\begin{array}{c}\text { Point of sale } \\
\text { advice }\end{array}$ & Product sampling & $\begin{array}{c}\text { Product Price } \\
\text { (CZK) }\end{array}$ \\
\hline $\mathbf{1}$ & under 10\% & YES & YES & under 500 \\
$\mathbf{2}$ & $11 \%-25 \%$ & NO & NO & $501-1,000$ \\
$\mathbf{3}$ & $26 \%-40 \%$ & & & $1,001-5,000$ \\
$\mathbf{4}$ & $41 \%$ and more & & & 5,001 and more \\
\hline
\end{tabular}

Source: own research

\section{Choice of conjoint methodology and profile rating method}

When choosing the conjoint methodology, the "full profile ratings" method was selected when the respondent rates profiles made up of all possible combinations of levels of their attributes (Hauser 2014). Hypothetical products, called profiles, are displayed to consumers. Consumers are also asked to rate profiles according to preference on the scale of 1 to 10 , where value 1 indicates the least preferred product and value 10 the most preferred product. The number of generated profiles in this model is a total of 256. According to the number of individual attribute levels listed in Table 2 , where Linear more $=$ the higher the value the better. Linear less $=$ the lower the value the better. 
Table 2: Model description

\begin{tabular}{|l|c|c|}
\hline \multicolumn{1}{|c|}{ Attributes } & $\begin{array}{c}\text { Number of } \\
\text { levels }\end{array}$ & $\begin{array}{c}\text { Relation to Ranks } \\
\text { or Scores }\end{array}$ \\
\hline Special offer & 4 & Linear (more) \\
POS advice & 2 & Discrete \\
Product sampling & 2 & Discrete \\
Product price & 4 & Linear (less) \\
\hline
\end{tabular}

Source: own research

To reduce the number of profiles an effective choice was made using the "fractional factorial design" method which deals with the problem of an excessive number of profiles to rate. The orthogonal field, used to reduce the number of profiles, is a specific subset of all possible combinations of the levels of attributes, in which each attribute level is in combination with each different attribute level with the same or at least proportional frequency, which ensures the independence of the main effects and results in the loss of information (Hauser 2014). The result of the choice using the above method is a total of 16 profiles (Table 3), which were again presented to consumers of the FAnn database using a web form sent in a regular information newsletter in September 2020:

Table 3: Profile choice and description

\begin{tabular}{|c|l|c|c|c|}
\hline Card ID & Special offer & POS advice & $\begin{array}{c}\text { Product } \\
\text { sampling }\end{array}$ & $\begin{array}{c}\text { Product price } \\
(\text { CZK })\end{array}$ \\
\hline 1 & $26 \%-40 \%$ & YES & NO & $1001-5000$ \\
2 & $11 \%-25 \%$ & YES & YES & $501-1000$ \\
3 & $26 \%-40 \%$ & NO & $501-1000$ \\
4 & under $10 \%$ & NO & $1001-5000$ \\
5 & under $10 \%$ & NES & NO & $501-1000$ \\
6 & $41 \%$ and more & NO & YES & $1001-5000$ \\
7 & $41 \%$ and more & NO & NO & under 500 \\
8 & $11 \%-25 \%$ & NO & YES & $1001-5000$ \\
9 & $11 \%-25 \%$ & NO & under 500 \\
10 & $41 \%$ and more & YES & YES & $501-1000$ \\
11 & under $10 \%$ & YES & YES & under 500 \\
12 & $26 \%-40 \%$ & NO & YES & 5001 and more \\
13 & $41 \%$ and more & YES & NO & 5001 and more \\
14 & under $10 \%$ & NO & YES & 5001 and more \\
15 & $11 \%-25 \%$ & YES & NO & 5001 and more \\
16 & $26 \%-40 \%$ & YES & YES & under 500 \\
\hline
\end{tabular}

Source: own research

\section{Results}

Cosmetic products, skincare products and luxury cosmetic products represent a stable, developing and dynamic market. The cosmetics sector is a globally long-term growing market when in 2019 it grew year-on-year by a total of 5.5\%. The global cosmetics industry is divided into six main categories. The biggest category is skincare products, which accounts for $36.4 \%$ of the global market in 2016. The currently estimated size of the global skincare market in 2025 is 189.3 billion USD (Statista 2020a). The luxury goods segment is a longterm economically significant and growing sector, when in 2018 revenues from the sale of luxury goods and services worldwide in comparison with 2017 increased by 5\% and reached $€ 1.2$ trillion (Bain 2019). In 2018 the global luxury cosmetics segment accounted for $24 \%$ of the income from luxury goods and recorded an increase of 3.5\% (Statista 2019). Income in the 
cosmetics segment in the Czech Republic in 2020 is estimated at 197.8 million USD. It is expected that the market will grow every year by $4.5 \%$ (Statista 2020b).

As the survey was targeted at the luxury skincare segment, for this reason only consumers from the FAnn parfumerie customer database were selected, meeting the above-mentioned conditions of luxury skincare product consumers. The total sample contained 1,104 responses and was characterized by a significantly higher number of women $(\mathrm{n}=1080,97.8 \%)$ and a smaller number were men $(n=24,2.2 \%)$. Due to the negligible number of men, filtration was carried out and the responses of 24 male respondents were no longer taken into account in further analyses. Therefore, the final sample was 1080, containing only female respondents. The predominant age category of the sample was defined by the age category of $35-44$ years $(\mathrm{n}=344,31.9 \%)$ and $25-34$ years $(\mathrm{n}=324,30 \%)$. The most listed was secondary education $(\mathrm{n}=526,48.7 \%)$ and more than a third of consumers $(\mathrm{n}=388,35.9 \%)$ gave an average monthly income ranging between CZK 20,001 and 30,000. Almost a half of consumers ( $\mathrm{n}=$ $521,48.2 \%)$ give their current marital status as married and the predominant part $(\mathrm{n}=742$, $68.7 \%$ ) of the collected sample described their predominant economic activity as being employees. A total of 294 consumers (27.2\%) live in cities with a population of over 100,000.

The data obtained was assessed using IBM SPSS statistical software, when the significance of the model was measured by the chi-square test of dependence between observed and estimated preferences where the correlation coefficient is statistically significant, if (sig. < 0.05), the model is significant (Table 4).

Table 4: Correlation between comparable and estimated preferences

\begin{tabular}{|l|c|c|}
\hline & Value & Sig. \\
\hline Pearson's R & 0.465 & 0.035 \\
\hline
\end{tabular}

Source: own research

In the following table (Table 5), we can see an estimated preference of factors (Utility estimate). The higher the value, the more preferred the factor for the consumer. This can well be seen in the special offer and the product price. The higher the discount is, the higher the preference and also the higher the price, the lower the preference. Customers do not prefer the point of sale advice and product sampling. They do not ascribe significant importance to these factors.

Table 5: Utility estimate

\begin{tabular}{|l|l|r|r|}
\hline & & Utility Estimate & Std. Error \\
\hline \multirow{2}{*}{ POS advice } & YES & $-0,688$ & 0,791 \\
& NO & 0,688 & 0,791 \\
\hline sampling & YES & $-0,813$ & 0,791 \\
& NO & 0,813 & 0,791 \\
\hline Special offer & under $10 \%$ & 1,275 & 0,708 \\
& $11 \%-25 \%$ & 2,55 & 1,415 \\
& $26 \%-40 \%$ & 3,825 & 2,123 \\
& $41 \%$ and more & 5,1 & 2,831 \\
\hline Product price & under 500 & $-0,325$ & 0,708 \\
(CZK) & $1,001-5,000$ & $-0,65$ & 1,415 \\
& 1,000 & $-0,975$ & 2,123 \\
(Constant) & 5,001 and more & $-1,3$ & 2,831 \\
\hline
\end{tabular}

Source: own research 
Based on the estimated preference coefficients of the given attributes, the preferences were then calculated for each profile. The most preferred is the Card ID 7 profile and the least preferred is the Card ID 14 profile. The preferences of all 16 profiles are shown in Table 6.

Table 6: Utility estimate all profiles

\begin{tabular}{|c|l|c|c|c|c|}
\hline Card ID & Special offer & POS advice & $\begin{array}{c}\text { Product } \\
\text { sampling }\end{array}$ & Product price & PREFERENCE \\
\hline 7 & $41 \%$ and more & NO & NO & under 500 & $\mathbf{2 . 0 1 9}$ \\
6 & $41 \%$ and more & NO & YES & $1,001-5,000$ & $\mathbf{1 . 6 7 6}$ \\
3 & $26 \%-40 \%$ & NO & NO & $501-1,000$ & $\mathbf{1 . 4 5 9}$ \\
9 & $11 \%-25 \%$ & NO & NO & under 500 & $\mathbf{1 . 2 4 1}$ \\
13 & $41 \%$ and more & YES & NO & 5,001 and more & $\mathbf{1 . 0 6 2}$ \\
8 & $11 \%-25 \%$ & NO & YES & $1,001-5,000$ & $\mathbf{0 . 8 9 8}$ \\
1 & $26 \%-40 \%$ & YES & NO & $1,001-5,000$ & $\mathbf{0 . 8 4 5}$ \\
5 & under $10 \%$ & NO & NO & $501-1,000$ & $\mathbf{0 . 6 8 1}$ \\
10 & $41 \%$ and more & YES & YES & $501-1,000$ & $\mathbf{0 . 5 7 8}$ \\
16 & $26 \%-40 \%$ & YES & YES & under 500 & $\mathbf{0 . 3 6}$ \\
12 & $26 \%-40 \%$ & NO & YES & 5,001 and more & $\mathbf{0 . 2 8 7}$ \\
15 & $11 \%-25 \%$ & YES & NO & 5,001 and more & $\mathbf{0 . 2 8 4}$ \\
4 & under $10 \%$ & YES & NO & $1,001-5,000$ & $\mathbf{0 . 0 6 7}$ \\
2 & $11 \%-25 \%$ & YES & YES & $501-1,000$ & $\mathbf{- 0 . 2}$ \\
11 & under $10 \%$ & YES & YES & under 500 & $\mathbf{- 0 . 4 1 8}$ \\
14 & under $10 \%$ & NO & YES & 5,001 and more & $\mathbf{- 0 . 4 9 1}$ \\
\hline
\end{tabular}

Source: own research

The results show that the most preferred profile is Card ID 7, which is the product with the lowest price, the highest special offer, and simultaneously, there is no possibility of product sampling or point of sale advice for this product.

\section{Discussion}

This study, which deals with consumer behaviour in the luxury skincare product segment, shows a different perception of luxury and prestige on the Czech market, the low significance of the influence of the attributes of brands and social status. Previous research in connection with consumer behaviour in the luxury segment speaks of concepts such as rarity or uniqueness (Rolling \& Sadachar 2018), the feeling of prestige (Correia et al. 2018), or of the concept of "identity, philosophy and culture" (Okonkwo 2009). The high price is highlighted as a significant luxury feature (Dubois et al. 2001). Likewise, the brand in this luxury segment is notable attribute (Duh \& Tshabalala 2019). The perceived social value (Correia et al. 2018) and strengthening of the social status (Kastanakis \& Balabanis 2014) are also an integral part of consumer behaviour in the luxury goods segment. Among the significant attributes of skincare products are above all improvement of physical appearance (Khuong \& Duyen 2016), youthfulness and increase of self-confidence (Junaid et al. 2013). Akhtar et al. (2016) state that consumers also choose skincare brands according to how they work on the skin. The efficacy of specific skin cream and the possibility of product sampling is therefore closely linked to skincare products. Furthermore, the importance is pointed out of the quality of services provided in relation to skincare products (Wu \& Chan 2011), which enhances consumer satisfaction and loyalty. Therefore, at the point of sale advice is certainly a service expected in connection with the offer of skincare products in the luxury goods segment. 
The results of this study carried out on the Czech market differ in some findings from previous claims made in the above studies. In this research, the price factor was also identified as a significant attribute influencing consumer choice, nevertheless, it was not the high (prestige) price, as a luxury goods attribute, but the low product price that consumers considered an important decision-making factor. Based on the two methodical steps, a questionnaire survey $(\mathrm{n}=892)$ and in-depth interviews, the influence of the brand as a luxury symbol was not included in the choice of the most significant attributes. The significance of the efficacy of skincare products, which brings improvement to the physical appearance and youthfulness, as stated by the study (Khuong \& Duyen 2016, Junaid et al. 2013, Akhtar et al. 2016), was a part of the final product profiles presented to consumers to make their choice (possibility of product sampling). Likewise, the importance of the quality of services (Wu \& Chan 2011) in this study is significant - point of sale advice was one of four of the most noteworthy skincare product attributes.

The final questionnaire survey with the application of the conjoint analysis, therefore, worked with the following attributes: possibility of sampling, point of sale advice, product price (product value) and a special offer (level of the offered product discount). The result of the survey points to the most popular skincare product in the luxury goods segment on the Czech market being the product with the lowest price (under CZK 500), with a high special offer (discount $40 \%$ and more), without the possibility of sampling the efficacy and quality of the product and without a professional point of sale advice. On the other hand, the least popular skincare product, apart from being the possibility of personal product sampling there, is the one with the highest price (CZK 5001 and more) and the lowest special offer level (under $10 \%)$.

\section{Conclusion}

As already been mentioned above, the results of this study partly differ from the significant factors influencing consumer behaviour in the luxury goods segment in general and with a specific link to skincare creams. Several effects may explain the different results. In the introduction to this article, the possible different perception of the term "luxury" of various cultures and individualities was already mentioned (Park \& Reisinger 2009). The study conducted by Semaan (2019) simultaneously points to various levels of luxury such as material or design. The perception of luxury in this segment of consumers, even if this concerns luxury skincare brands on the Czech market, is not so significant and the term "luxury", in relation to skincare products, is not decisive for consumers when making a purchase. The level of income of the resulting study sample also needs to be considered when the share of the income category $(\mathrm{CZK} 30,001-50,000)$ was only $11.3 \%(\mathrm{n}=122)$ and the highest income category (more than CZK 50 000) only 11.94\% $(n=21)$. The level of income significantly influenced the perception and consumption of luxury goods when the factor of wealth is traditionally accepted as a key determinant of luxury consumption (Dubois \& Duquesne 1993).

Simultaneously, the perception of luxury and luxury brands may also be influenced by cultural differences. This study is drawn up in the Czech Republic, a relatively new market economy in Central and Eastern Europe (CEE), which since 1989 has undergone a deep transformation from communism to capitalism and in 2004 became a member of the European Union (EU). Currently, it is one of the economically most developed countries of Central and Eastern Europe (IMF 2019). Before 1989, prior to the breakup of the Eastern Bloc, it was difficult to practice western style consumerism in Central and Eastern Europe, especially in the Czech Republic. The years of isolation brought a lack of knowledge, not just of the 
diverse range of goods, but also of the various forms of advertising and communication used by multinational advertisers (Mellow 1995). The perception of luxury and brands belonging to the luxury segment may thus be different or "lower", compared to the established western economies, where most consumer surveys and models of consumer behaviour are carried out.

A further reason for the above results of the study of Czech consumer behaviour is the higher sensitivity to discounts, which is confirmed by further studies and surveys. The study, according to Starzyczná et al. (2015) points out the significant interest of Czech consumers in promotional product discounts. In the research results, Klapilova (2016) adds that brands are considered symbols and guarantees of quality, but they are also perceived by consumers as unnecessarily expensive. Finally, a positive approach to discount offers was observed. The significance of this influencing price/discount factor may also be influenced by the income as well as the age of the consumer.

The results of the study point to the number of opportunities for luxury skincare product traders, retailers and marketers. The finding that a certain group of consumers tends to prefer a low price and a significant special offer even though shopping in the luxury skincare brand environment is undoubtedly, important. The cultural differences of the Czech consumers need to be considered and these findings need to be taken into account when compiling business and marketing plans. The sensitivity to the level of price and any discount must be sensitively incorporated into advertising communications offering luxury skin creams with regard to the image of luxury brands. Simultaneously, the demographic sample must also be taken into account, based on which study was carried out and the results applied specifically to this target group of consumers. Further consumers of various ages, a different economic activity or income, may have a different perception of luxury, prestige or social status.

Certainly, the result of this research can be used not only by FAnn perfumery chain and other perfumery chains on the Czech market such as Douglas, Sephora and Marionnaud. Can be effectively used in planning specific marketing activities, campaigns and support key business decision in the field of luxury skin care. Based on this knowledge, they can actively and intensively work on their strategies, which may be the source of key competitive advantage for companies indicated. Additionally, companies operating in luxury consumption in general, can also apply results coming out of this research, as the knowledge of consumer behaviour is nowadays the key knowledge of successful companies.

Limitations of this research lie in the specific target group which is connected to this concrete luxury skincare segment via FAnn perfumery chain. Although the size of the research sample is quite large, and the market share of this perfumery chain is significant, still there is a gap for further research for other consumer groups such as millennials, men or wealthy consumers with specific behaviour.

\section{Acknowledgement}

This study is the result of the research project supported by the Faculty of Business and Economics, MENDEL University, financed as part of the project of the IGA (Internal Grant Agency of the FBE) No. PEF_DP_2020002, entitled "Buying Decision Process of Consumers of Skin Products Following on from the Distribution Point of Sale". 


\section{References}

[1] AJITHA, S. and V. J. SIVAKUMAR, 2017: Understanding the effect of personal and social value on attitude and usage behavior of luxury cosmetic brands, Journal of Retailing and Consumer Services, 39,: 103-113

[2] AKHTAR, N., U. I. SIDDIQI, A. ASHRAF and M. LATIF, 2016. Impact of a Brand Equity on Consumer Purchase Decision in L'Oreal Skincare Products, International Review of Management and Business Research, 5(3): 808.

[3] BAIN AND COMPANY 2018. Luxury Goods Worldwide Market Study 2018. [Online]. Available at: https://www.braintrustgroup.de/wpcontent/uploads/2019/01/bain_digest_luxury_goods_worldwide_market_stu dy_fall_winter_2018-2.pdf [Accessed: 2 February 2019].

[4] BAHAMONDE - BIRKE, F. J., I. NAVARRO and J. de DIOS ORTÚZAR, 2017. If you choose to not decide, you still have made a choice. J. Choice Model, 22: 13-23.

[5] CORREIA, A., M. KOZAK and S. KIM, 2018. Luxury shopping orientations of Mainland Chinese tourists in Hong Kong: Their shopping destination. Tourism Economics, 24 (1): 92-108.

[6] DUBOIS, B., G. LAURENT and S. CZELLAR, 2001. Consumer Rapport to Luxury: Analyzing Complex and Ambivalent Attitudes, Consumer Research Working Paper, No. 736; HEC: Jouy-en-Josas, France

[7] DUBOIS, B. and P. DUQUESNE, 1993. The market for luxury goods: Income versus culture. European Journal of Marketing, 27: 35-44.

[8] DUH, I. H. and B. TSHABALALA, 2019. Aspects of celebrity endorsements and brand values influencing young adults' attitude and purchase intention of cosmetics brands in South Africa, Global Alliance of Marketing \& Management Association: Global Fashion Management Conference [Online]. Available at: http://db.koreascholar.com/article.aspx?code=372675 [Accessed: 2 February 2019].

[9] GENTINA, E., L. J. SHRUM and T. M. LOWREY, 2016. Teen attitudes toward luxury fashion brands from a social identity perspective: a cross-cultural study of French and U.S. teenagers. J. Bus. Res. 69 (12): 5785-5792.

[10] HAIR, J. F., 2010. Multivariate data analysis: a global perspective: 266 - 267

[11] HAN, Y. J., J. C. NUNES and X. DRĖZE, 2010. Signaling status with luxury goods: the role of brand prominence. J. Mark. 74 (4): 15-30.

[12] HAUSER, J. R., 2014. Note on conjoint analysis, Massachusetts Institute of Technology [Online], [Accessed. 2 March 2020].

[13] HAILIN, CH., Z. JOYCE and Y. JUN, 2016. Consumer perception and consumption behavior regarding luxury products in the fashion industry, International Journal of Business, Marketing, \& Decision Science, Vol. 9 Issue 1: 84-96. 13p

[14] CHAN, W. Y., C. K. M. TO and W. C. CHU, 2015. Materialistic consumers who seek unique products: how does their need for status and their effective response facilitate the repurchase intention of luxury goods? J. Retail. Consum. Serv. 27: 1-10.

[15] KHUONG, M. N. and H. T. M. DUYEN, 2016. Personal factors affecting consumer purchase decision towards men skincare products: A study on Ho Chi Minh City, Vietnam. 
[16] KLAPILOVA KRBOVA, P., 2019. Generation Y Attitudes towards Shopping: A Comparison of the Czech Republic and Slovakia, Journal of Competitiveness, 8(1): 3854

[17] KOUDELKA, J., 2006: Spotřební chování a segmentace trhu. University of Economics and Management.

[18] LOUREIRO, S. M. C., 2012: Consumer-brand relationship: Foundation and state-of-theart. In: KAUFMANN, H. R., PANNI, M. F. A. K. Customer-Centric Marketing Strategies: Tools for Building Organizational Performance. Hershey: IGI Global: 413434. ISBN 978-1-4666-2524-2.

[19] IASTAT, 2001. Analýza spotřebitelských preferencí v programových systémech SAS a SPSS. IASTAT - Interaktivní učebnice statistiky [Online], Available at: https://iastat.vse.cz/preference.html [Accessed: 24 November 2019]

[20] IMF, 2019: Czech Republic: 2019 Article IV Consultation-Press Release and Staff Report [Online], Available at: https://www.imf.org/en/Publications/CR/Issues/2019/06/12/Czech-Republic-2019-

Article-IV-Consultation-Press-Release-and-Staff-Report-46989 [Accessed 31 July 2020].

[21] JUNAID A. B., R. NASREEN and F. A. J. HAMDARD, 2013. A Study on the Purchase Behavior and Cosmetic Consumption Pattern among Young Females in Delhi and NCR, Journal of Social and Development Sciences Vol. 4, No. 5: 205-211.

[22] KASTANAKIS, M. N. and G. BALABANIS, 2014. Explaining variation in conspicuous luxury consumption: an individual differences' perspective. J. Bus. Res. 67 (10): 21472154.

[23] MELLOW, C., 1995. Culture clash: Western advertisements need more than fine-tuning. In Business Russia (Vol. 1, p. 1). London: Economist Intelligence Unit.

[24] OKONKWO, U., 2009. Sustaining the luxury brand on the internet. J. Brand Manag. 16 (5/6): 302-310.

[25] PARK, K. S. and Y. REISINGER, 2009. Cultural differences in shopping for luxury goods: Western, Asian, and Hispanic tourists. Journal of Travel \& Tourism Marketing, 26(8): 762-777.

[26] ROLLING, V. and A. SADACHAR, 2018. Are sustainable luxury goods a paradox for millennials? Social Responsibility Journal, Vol. 14 No. 4: 802-815.

[27] SEMAAN, R. W., Val LINDSAY, P. WILLIAMS and N. ASHILL, 2019. The influence of gender roles in the drivers of luxury consumption for women: Insights from the gulf region. Journal of Retailing and Consumer Services [Online], 51, 165-175 DOI: 10.1016/j.jretconser.2019.06.006. ISSN 09696989. Available at: https://linkinghub.elsevier.com/retrieve/pii/S0969698918311755 [Accessed 12 April 2020].

[28] STARZYCZNÁ H., M. STOKLASA and K. MATUŠÍNSKÁ, 2015. Influence of Product Leaflets on Purchasing Behaviour in Times of Crisis. Acta Universitatis Agriculturae et Silviculturae Mendelianae Brunensis, 63(4): 1357-1363.

[29] STATISTA, 2019. Statistics \& Facts. [Online], Available at: https://www.statista.com/study/55494/luxury-goods-report/ [Accessed 20 April 2020]. 
[30] STATISTA, 2020a. Statistics \& Facts. [Online], Available at: https://www.statista.com/statistics/297070/growth-rate-of-the-global-cosmetics-market/ [Accessed 20 April 2020].

[31] STATISTA, 2020a. Statistics \& Facts. [Online], Available at: https://www.statista.com/statistics/254612/global-skin-care-market-size/ [Accessed 20 April 2020].

[32] STATISTA, 2020b. Statistics \& Facts. [Online], Available at: https://www.statista.com/outlook/70010000/132/cosmetics/czechia [Accessed 20 April 2020].

[33] TAK, P. and A. PAREEK, 2016. Consumer attitude towards luxury brands: An empirical study. Journal of Brand Management, 13 (1): 7-19

[34] VIDYAPEETHAM, A. V., 2018. A study on factors influencing cosmetic buying behavior of consumers [online],]. Available at: https://pdfs.semanticscholar.org/05c8/fd9e84401f9768776e2dece8406b762aae56.pdf [Accessed 23 July 2021].

[35] WU, SI. and HJ. CHAN, 2011. Perceived service quality and self-concept influences o TOTAL QUALITY MANAGEMENT \& BUSINESS EXCELLENCE Volume: 22 Issue: 1 Pages: 43-62 DOI: 10.1080/14783363.2010.529645

[36] YEH, I. C., C. H. LIEN, T. M. TING, Y. Y. WANG and C. M. TU, 2010. Cosmetics purchasing behavior - An analysis using association reasoning neural networks. Expert System with Applications 37 (10): 7219-7226 